\title{
Leopard Panthera pardus fusca Density in the Seasonally Dry, Subtropical Forest in the Bhabhar of Terai Arc, Nepal
}

\author{
Kanchan Thapa, ${ }^{1}$ Rinjan Shrestha, ${ }^{2}$ Jhamak Karki, ${ }^{3}$ \\ Gokarna Jung Thapa, ${ }^{4}$ Naresh Subedi, ${ }^{5}$ Narendra Man Babu Pradhan, ${ }^{4}$ \\ Maheshwar Dhakal, ${ }^{6}$ Pradeep Khanal, ${ }^{4}$ and Marcella J. Kelly ${ }^{1}$ \\ ${ }^{1}$ Department of Fish and Wildlife Conservation, Virginia Tech, Blacksburg, Virginia, VA 24061, USA \\ ${ }^{2}$ Eastern Himalayas Program (WWF-US), C/O WWF-Canada, 245 Eglinton Avenue E, Toronto, ON, Canada M4P 3J1 \\ ${ }^{3}$ Nepal Engineering College-Center for Post Graduate Studies, Kathmandu 44600, Nepal \\ ${ }^{4}$ WWF Nepal, Kathmandu 44600, Nepal \\ ${ }^{5}$ National Trust for Nature Conservation, Lalitpur 44700, Nepal \\ ${ }^{6}$ Department of National Park and Wildlife Conservation, Kathmandu 44600, Nepal
}

Correspondence should be addressed to Kanchan Thapa; kanchan1@vt.edu

Received 14 April 2014; Revised 9 June 2014; Accepted 12 June 2014; Published 16 July 2014

Academic Editor: Tomasz S. Osiejuk

Copyright (C) 2014 Kanchan Thapa et al. This is an open access article distributed under the Creative Commons Attribution License, which permits unrestricted use, distribution, and reproduction in any medium, provided the original work is properly cited.

\begin{abstract}
We estimated leopard (Panthera pardus fusca) abundance and density in the Bhabhar physiographic region in Parsa Wildlife Reserve, Nepal. The camera trap grid, covering sampling area of $289 \mathrm{~km}^{2}$ with 88 locations, accumulated 1,342 trap nights in 64 days in the winter season of 2008-2009 and photographed 19 individual leopards. Using models incorporating heterogeneity, we estimated $28( \pm$ SE 6.07$)$ and $29.58( \pm$ SE 10.44) leopards in Programs CAPTURE and MARK. Density estimates via 1/2 MMDM methods were $5.61\left( \pm\right.$ SE 1.30) and $5.93( \pm$ SE 2.15$)$ leopards per $100 \mathrm{~km}^{2}$ using abundance estimates from CAPTURE and MARK, respectively. Spatially explicit capture recapture (SECR) models resulted in lower density estimates, $3.78( \pm$ SE 0.85$)$ and $3.48( \pm$ SE 0.83 ) leopards per $100 \mathrm{~km}^{2}$, in likelihood based program DENSITY and Bayesian based program SPACECAP, respectively. The $1 / 2$ MMDM methods have been known to provide much higher density estimates than SECR modelling techniques. However, our SECR models resulted in high leopard density comparable to areas considered better habitat in Nepal indicating a potentially dense population compared to other sites. We provide the first density estimates for leopards in the Bhabhar and a baseline for long term population monitoring of leopards in Parsa Wildlife Reserve and across the Terai Arc.
\end{abstract}

\section{Introduction}

The leopard (Panthera pardus fusca Meyer, 1794) is one of the most widely distributed felids across the forested landscapes of the Indian subcontinent $[1,2]$. Being a habitat generalist [3], the leopard has a wider fundamental niche than its larger congener, the tiger (Panthera tigris tigris Linnaeus), in terms of the habitat and area it occupies [4], extending from alluvial floodplains, subtropical deciduous moist and dry habitat in lowlands and Siwaliks, temperate deciduous forest habitat in mid hills and high mountains, to dry alpine forest in the Himalayas [5]. Leopards occur sympatrically with tigers in Nepal, India, and Bhutan [6-8].
The tiger, being an apex predator, appeals to the public and serves as a flagship species [9]. Perceived as more tolerant of anthropogenic influences, the leopard on the other hand has received less attention from conservationists despite its important functional role within ecosystems, including its potential to cause trophic cascades [10], its impact on mesopredators $[11,12]$, and its competitive role within its guild $[13,14]$. In the human dominated landscape of today's Indian subcontinent, habitat destruction and fragmentation remain major threats to leopards [4] and leopard numbers are declining due to both direct mortality and decreases in prey populations [15]. 


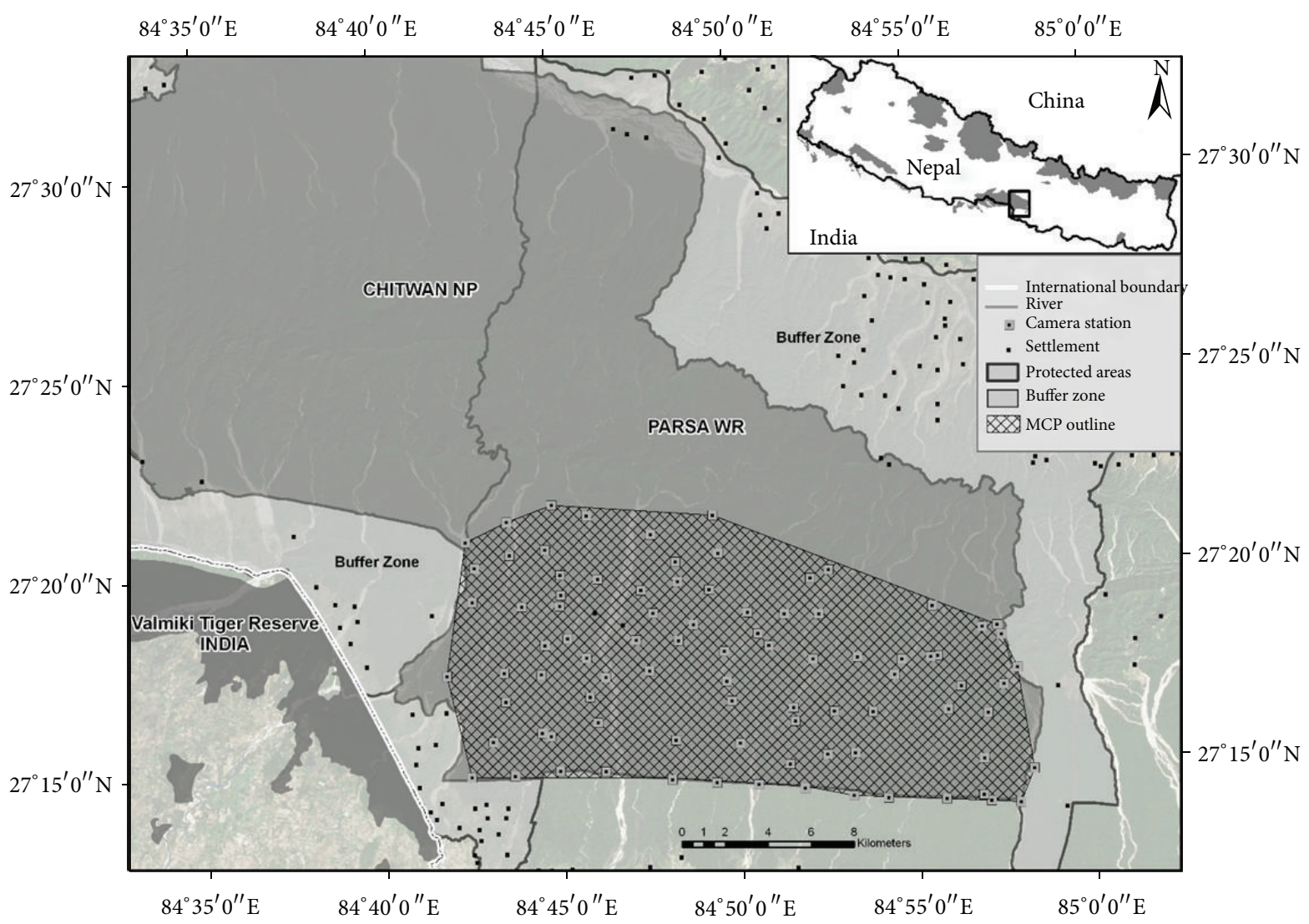

FIgURE 1: Study areas showing the spatial location of camera traps in the Bhabhar region and the effective sampling area formed by drawing a minimum convex polygon surrounding the outermost camera trap locations. The area of MCP (minimum convex polygon) is $289 \mathrm{~km}^{2}$.

In contrast to tigers, whose population sizes and trends have been intensively studied in multiple sites across the Indian subcontinent [8,16-23], fewer studies have estimated leopard population sizes across both protected [24-26] and nonprotected areas [27], representing an array of habitat types in India. In Nepal, even fewer studies are available on leopard demography only representing alluvial floodplains, grasslands, and deciduous forest from Chitwan [28, 29] and Bardia National Parks [30]. However, there are no estimates of leopard density from seasonally dry subtropical forest in the Bhabhar region. Bhabhar is the alluvial apron of sediments washed down from the Siwaliks [31] and represents a key physiographic region extending to the "Terai zone" across the Terai Arc Landscape (Terai Arc). Hence, lack of information from Bhabhar habitat has hindered an overall assessment of leopard conservation status.

We estimate the abundance and density of leopards from the protected area within Bhabhar using a photographic capture-recapture sampling framework [32-34]. This approach is widely acknowledged as a robust tool for estimating population abundance of elusive wild cats with individually distinct pelage patterns $[15,20]$. We use traditional techniques of estimating the density using the ad hoc method of adding a buffer area around the polygon formed by connecting outer camera trap locations to account for edge effects (animals that do not occur entirely within trapping grid but have home range overlapping the edge of the grid). These buffering methods include using an estimate of home range radius derived from GPS or radio telemetry $[35,36]$ or the common technique of using half of the mean maximum distance moved ( $1 / 2 \mathrm{MMDM})$ by animals within the trap array as a surrogate for home range radius $[18,37,38]$. However, these ad hoc approaches have come under scrutiny because they are heavily influenced by small sample size, camera spacing, and extent of sampling grid relative to the animal's home range $[35,39,40]$. To address the shortcomings of the traditional approach in estimating leopard density, we also use recently developed spatially explicit capture recapture (SECR) techniques that use spatial information more directly in the density estimation process [40-43]. We compare the maximum likelihood [44] and Bayesian [45] SECR approaches in estimating density without the need to estimate an effective trapping area using the traditional ad hoc buffering approach. We present the result from both traditional and SECR approaches allowing us to compare our leopard density estimates with other studies in South Asia (Nepal, India, and Bhutan).

\section{Materials and Methods}

The study was carried out in Parsa Wildlife Reserve (PWR; $27^{\circ} 15^{\prime} \mathrm{N}, 84^{\circ} 40^{\prime} \mathrm{E}$; Figure 1) in the south-central lowland Terai 
of Nepal. Encompassing over $499 \mathrm{~km}^{2}$, PWR is the largest wildlife reserve in the country and is contiguous to Chitwan National Park to the west. PWR is made up mostly of Churia hills (the outermost foothills of Himalayas) and Bhabhar regions, a rugged and highly porous landscape largely comprised of coarse alluvial deposits where streams disappear into permeable sediments [31]. PWR has a monsoonal humid climate with more than $85 \%$ of the annual precipitation $(2180 \mathrm{~mm})$ occurring between July and October. The dry season occurs for 8 months between November and June [46].

The vegetation can best be described as subtropical, dry, deciduous forest with colonizing Saccharum spontaneum and Imperata cylindrica on the dry riverbeds and the floodplains, to a climax Sal (Shorea robusta) forest on Bhabhar and hillsides [47]. The reserve supports a diverse mammalian fauna in addition to leopards, including carnivores such as the tiger (Panthera tigris tigris), dhole (Cuon alpinus), striped hyena (Hyaena hyaena), golden jackal (Canis aureus), Indian fox (Vulpes bengalensis), and ratel (Mellivora capensis). The principle wild prey species of the leopard include large size animals (>50 kg): gaur (Bos gaurus), sambar (Rusa unicolor), and nilgai (Boselaphus tragocamelus); medium size animals (20-50 kg): chital (Axis axis), muntjac (Muntiacus muntjak), and wild pig (Sus scrofa); and small size animals $(<20 \mathrm{~kg})$ : common langur (Semnopithecus entellus) and rhesus monkey (Macaca mulatta). The combined ungulate prey density is estimated to be 6.6 individuals ( \pm SE 1.1) per $\mathrm{km}^{2}$ [48]. Two of the settlements comprising approximately 100 households in Rambhori and Bhata in the core area of the reserve have been recently relocated [49]. This is an event that is expected to trigger the recovery of carnivores within the reserve, making our density estimation an important baseline study. Illegal livestock grazing along the buffer zone is believed to reduce forage for wild ungulates, and livestock has been found grazing inside the reserve as far as $5 \mathrm{~km}$ from the reserve boundary. Photographic evidence from camera trap pictures [50] suggests that illegal poaching of wild prey is a direct threat to the carnivore populations in the reserve.

2.1. Field Methods. We conducted a camera trap survey for 64 days across a $289 \mathrm{~km}^{2}$ core area of the reserve between December 2008 and March 2009. We followed the standard study design approaches prescribed for large felids at sites that had intensive signs of their usage $[18,19,51]$. We first carried out extensive sign surveys for leopards $[2,52]$ across 42 transect routes spread across the core area of the reserve amounting to $702 \mathrm{~km}$ searched on foot. These transect surveys enabled us to choose key locations for installing camera traps and identifying survey blocks that covered a large area without leaving potential gaps in our survey grid.

We selected 88 camera-trap locations spread throughout the study area based on the presence of leopard tracks, scats, scrapes, and other signs of use. To maximize capture probability, we positioned our camera traps along forest roads, trails, and dry stream beds, the habitat features known as leopard travel routes $[6,53]$. The spacing between cameratrap locations (Figure 1) was maintained at approximately $1.9 \mathrm{~km}( \pm \mathrm{SE} 0.06)$ [2]. At each location, we used 2 passive
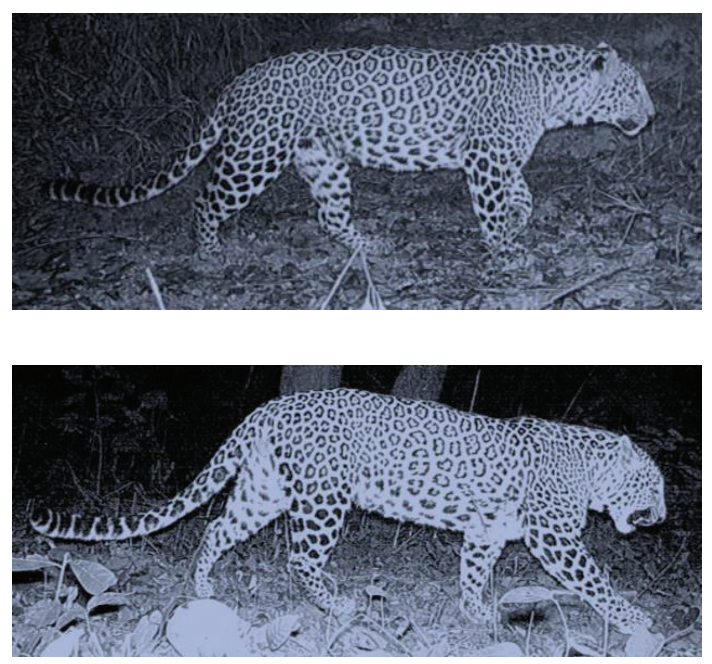

FIGURE 2: Identical pelage patterns from the same leopard in PWR as displayed in photographic captures from different camera traps.

digital camera traps (Moultrie D50, Moultrie Feeders, USA) activated by animal movement and placed on either side of the trail to photograph both right and left flanks of leopards $[2,32]$. Each camera trap was active for $24 \mathrm{~h}$ and was checked on alternate days for proper recording of capture events, date, time, and any possible malfunctions.

We divided the study area into four "trapping blocks" each measuring an average area of $70.5 \mathrm{~km}^{2}( \pm$ SE 7.54$)$. We placed 22 camera stations per block resulting in an average of 32.2 camera stations per $100 \mathrm{~km}^{2}$. Each location was sampled for 16 consecutive days resulting in 16 encounter occasions, each consisting of capture data drawn from one day's trapping in each of the blocks [2]. After 16 days, cameras were moved to the next block until all 4 survey blocks were completed.

2.2. Individual Identification. Two investigators independently identified the photos for individual identification to build consensus on individual leopard identity. Individual leopards were identified based on their unique rosette patterns on the flanks, limbs, and forequarters [54] and given unique identification numbers (Figure 2) as done in other studies $[24,26,27,55]$.

2.3. Population Estimation. We followed the traditional capture-recapture analytic techniques used for estimating population sizes of large felids from remote camera data [2, $18,19]$. We constructed capture histories for each individual leopard from photographic captures and assigned them to the appropriate encounter occasions (refer to Otis et al. [33] and Karanth and Nichols [2] for detail). We used two separate approaches to statistically test the assumption of population closure.

We first used the closure test implemented in program CAPTURE [56]. We then used the Stanley and Burnham [57] closure test that assumes only time variation in recapture probability using the Pradel model [58] in Program MARK v. 5.1 [59]. The Pradel model evaluates geographic closure by estimating the site fidelity $(\phi)$, immigration $(f)$, and 
recapture probability $(p)$ with regard to entry and exit into or out of the sampling area under assumption of the closure for the leopard population over our 64-day sampling period.

We used the closed population models [33] implemented in program CAPTURE for estimation of overall capture probability $(\widehat{p})$ and abundance $(\widehat{N})$, using several different models that can incorporate effects of ecological and sampling-related factors (for details refer to $[2,7]$ ). We also used the Huggins closed capture with heterogeneity modeling platform in program MARK $[33,59,60]$ to calculate abundance estimates. These models use a maximum likelihood framework and we fit 8 models of Otis et al. [33], which allow capture probabilities to vary over time $(p(t)=c(t))$, by individual's heterogeneity $(p(h)=c(h))$, due to a behavioral response (initial capture being different from recapture probabilities, $p(\cdot) \cdot c(\cdot)$ ) along with null model (with no variation in capture probabilities, $p(\cdot)=c(\cdot)$ ), and combinations of the above factors. Model input includes the one time winter season capture histories with 16 encounter occasions. We ranked all the models using sample size-adjusted Akaike's Information Criterion (AIC) [61] and considered all models with $\Delta \mathrm{AIC}_{\mathrm{c}}<2$ as competing models [62].

2.4. Density Estimation. To convert our abundance estimates from programs CAPTURE and MARK to densities, we used the traditional 1/2 MMDM [18, 37] and full MMDM [63] approaches to calculate the buffer strip surrounding our camera traps to determine the effective trap area (ETA). The 1/2 MMDM and full MMDM were calculated from photographed individuals trapped in more than one location and we buffered each camera trap and dissolved the overlapping areas to calculate the ETA. We then divided our population estimates from CR (capture-recapture) analysis by total ETA to determine density. We used the delta method to calculate the variance in density estimates [64].

We used two SECR approaches to estimate leopard density: a maximum likelihood modeling framework (SECRML) implemented in program DENSITY [41] and a Bayesian modeling framework (SECR-B) $[45,65]$ implemented in program SPACECAP [66]. These methods allow us to compare our results with recent studies on leopard density estimates using SECR-ML models $[25,67,68]$ and using SECR-B [25, 27, 29, 67].

In program DENSITY v. 5.0 [41], we first modeled to select the appropriate detection (observational) process as either half-normal, hazard rate, or negative exponential. Using the selected detection function, we then allowed $g_{0}$ (the capture probability at the hypothetical center of an individual's home range) and sigma (a function of the scale of animal movement) to vary using 2-class, finite mixture (h2) to represent heterogeneity and/or a behavioral response (b). Thus, a hazard detection function model with constant $g_{0}$ and 2-class finite mixture of sigma would be represented as $\mathrm{HZ} g_{0}(\cdot) \operatorname{sig}(h 2)$. We used the estimated log likelihood and root-pooled spatial variance (RPSV) of varying integration buffers [41, 69] for determining the appropriate buffer size. We ranked all the models using sample size-adjusted Akaike's Information Criterion $\left(\mathrm{AIC}_{\mathrm{c}}\right)$ and considered all models
TABLE 1: Summary statistics for photographic capture-recapture data on leopards in PWR.

\begin{tabular}{lc}
\hline Survey Summary & Value \\
\hline Number of camera trap stations & 88 \\
Sampling occasions (1 day each) & 16 \\
Effort (trap nights) & 1,342 \\
$\begin{array}{l}\text { Number of independent photographs } \\
\text { Leopard activity index (number of } \\
\text { photographs per 100 trap nights) }\end{array}$ & 45 \\
Total number of individuals caught, $M_{t+1}$ & 3.35 \\
Total number of captures & 19 \\
Number of individual animals caught once & 39 \\
Number of individual animals caught more & 14 \\
than once & 5 \\
Survey period & 21 December 2008-3 \\
& March 2009 \\
\hline
\end{tabular}

with $\triangle \mathrm{AIC}_{\mathrm{c}}<2$ as competing models. We used the model averaging techniques to determine final density estimates [62]. We report the unconditional variance estimates for the model average estimates.

For the SECR-B approach, we used program SPACECAP [66] implemented in $\mathrm{R}$ package v. 3.0.1 [70] for estimating leopard density [65]. We buffered $15 \mathrm{~km}$ around the sampling area to represent the probable extent of leopard home range centers and generated a grid of hypothetical home range centers with equally spaced points $(n=8150)$, each $0.336 \mathrm{~km}$ apart. This resulted in an area of $1,389 \mathrm{~km}^{2}$ of leopard habitat over which these activity centers were uniformly distributed, after removing the $674 \mathrm{~km}^{2}$ area of settlements (villages and agriculture areas: Rambhori, Bhata, Nirmal basti and amlekhganj). We used three standard input data files (animal capture locations and dates, trap deployment dates and locations, and hypothetical activity centers) and we assumed the half normal detection function. We performed 52,000 iterations, of which the initial 2,000 were discarded as the burn-in period, a thinning rate was set at 20, and we used an augmentation value of 180 individuals (more than five times the expected number of animals). We evaluated results using the Geweke diagnostic [71] and $z$-score statistics of $\mid z$-score $\mid$ more than 1.6 implying lack of convergence [66]. We produced the pixelated density map showing the estimated leopard densities per pixel of size $0.336 \mathrm{~km}^{2}$ using ArcGIS 10.1 .

2.5. Comparison of Leopard Estimates. We compiled information on leopard densities from protected areas across their range in Nepal, India, and Bhutan and present cross-site comparisons of density and habitat type and describe density estimates based on type of modeling approach used and their corresponding standard errors.

\section{Results}

3.1. Sampling Effort and Number of Individual Leopards Captured. After discarding 66 trap nights of camera malfunctions, we amassed 1,342 trap nights and obtained 120 identifiable photographs comprised of 64 right flanks and 56 left flanks of leopard photographs (Table 1). Two investigators 
TABLE 2: Closure test and model selection (after Otis et al. [33]) for leopard population size estimation using photographic capture-recapture data from Parsa Wildlife Reserve in Program CAPTURE. DFS is the discriminant function score. The $M_{b}$ shows the Behavioral effect, while $M_{h}$ shows the heterogeneity effect and the $M_{o}$ shows the constant null model.

\begin{tabular}{|c|c|c|c|c|c|c|c|c|}
\hline \multicolumn{2}{|c|}{ Closure Test } & \multirow{2}{*}{$\begin{array}{c}\text { Individuals } \\
\text { Caught }\left(M_{t+1}\right)\end{array}$} & \multirow{2}{*}{$\begin{array}{c}\text { Total } \\
\text { Captures }(n)\end{array}$} & \multirow{2}{*}{ Models } & \multirow{2}{*}{ DFS } & \multirow{2}{*}{$\begin{array}{l}\text { Capture } \\
\text { Probability } \widehat{p}\end{array}$} & \multirow{2}{*}{$\begin{array}{l}\text { Total Abundance, } \\
\qquad \widehat{N}(\widehat{\mathrm{SE}}[\widehat{N}])\end{array}$} & \multirow{2}{*}{$\begin{array}{l}\text { 95\% Confidence } \\
\text { Interval (CI) }\end{array}$} \\
\hline $\mathrm{Z}$ & $p$ & & & & & & & \\
\hline \multirow{4}{*}{0.988} & \multirow{4}{*}{0.8383} & \multirow{4}{*}{19} & \multirow{4}{*}{39} & $M_{h}$ & 1.00 & 0.0871 & $28(6.07)$ & $22-48$ \\
\hline & & & & $M_{o}$ & 0.95 & 0.1115 & $22(2.45)$ & $20-31$ \\
\hline & & & & $M_{b h}$ & 0.84 & 0.0453 & $36(27.05)$ & $21-173$ \\
\hline & & & & $M_{b}$ & 0.62 & 0.0453 & $36(27.05)$ & $21-173$ \\
\hline
\end{tabular}

TABLE 3: Model selection summary for geographic closure for the leopard population in Parsa Wildlife Reserve in program MARK. Phi represents the site fidelity. $p$ is the recapture probability and $f$ is immigration onto the study site. Parameter with "." indicates a constant value and with "1" and/or " 0 " indicates parameter is fixed. $\mathrm{AIC}_{\mathrm{c}}$ is Akaike's information criterion corrected for small sample size and difference in $\mathrm{AIC}$ value between top model and $i$ th model is represented by $\Delta \mathrm{AIC}_{\mathrm{c}}$. Weight of support for each model is $\mathrm{AIC}_{\mathrm{c}}$ weights, $\omega$.

\begin{tabular}{|c|c|c|c|c|c|c|}
\hline Model & $\mathrm{AIC}_{\mathrm{c}}$ & $\Delta \mathrm{AIC}_{\mathrm{c}}$ & $\begin{array}{c}\mathrm{AIC}_{\mathrm{c}} \text { weights } \\
(\omega)\end{array}$ & $\begin{array}{c}\text { Model } \\
\text { likelihood }\end{array}$ & $\begin{array}{c}\text { Number of } \\
\text { parameters }(k)\end{array}$ & Deviance \\
\hline$[\operatorname{Phi}(1) p($ time $) f(0)]$ & 263.1642 & 0 & 0.89645 & 1 & 16 & 100.0934 \\
\hline$[\operatorname{Phi}(1) p($ time $) \cdot f(\cdot)]$ & 268.4008 & 5.2366 & 0.06538 & 0.0729 & 17 & 98.9144 \\
\hline$[\mathrm{Phi}(\cdot) p($ time $) f(0)]$ & 269.5798 & 6.4156 & 0.03626 & 0.0404 & 17 & 100.0934 \\
\hline$[\operatorname{Phi}(\cdot) p($ time $) \cdot f(\cdot)]$ & 275.458 & 12.2938 & 0.00192 & 0.0021 & 18 & 98.9144 \\
\hline
\end{tabular}

TABLE 4: Leopard abundance from Parsa Wildlife Reserve was estimated using Huggins closed captures with heterogeneity models in program MARK (Pledger [60], White and Burnham [59]). $M_{b}[p(\cdot) \cdot c(\cdot)]$ is the behavioral effect. $M_{h}[p(h)=c(h)]$ is the heterogeneity effect, while $M_{o}[p(\cdot)=c(\cdot)]$ is the constant null model. $\mathrm{AIC}_{\mathrm{c}}$ represents Akaike's information criterion corrected for the small sample size. Difference in AIC value between top model and $i$ th model $\left(\Delta \mathrm{AIC}_{\mathrm{c}}\right.$ ). Weight of support for each model $\left(\mathrm{AIC}_{\mathrm{c}}\right.$ weights, $\omega$ ). $\widehat{N}$ represents abundance estimate, while SE represents standard errors. Model averaged density estimates and standard errors are given in bold. ${ }^{*}$ represents model selected for inferring parameter estimates.

\begin{tabular}{|c|c|c|c|c|c|c|c|}
\hline Model & $\mathrm{AIC}_{\mathrm{c}}$ & $\Delta \mathrm{AIC}_{\mathrm{c}}$ & $\begin{array}{c}\text { AIC }_{c} \text { Weights } \\
(\omega)\end{array}$ & $\begin{array}{c}\text { Model } \\
\text { likelihood }\end{array}$ & $\begin{array}{c}\text { Number of } \\
\text { parameters }(k)\end{array}$ & $\begin{array}{l}\text { Abundance estimate } \\
\qquad \widehat{N}(\widehat{\mathrm{SE}}[\widehat{N}])\end{array}$ & $\begin{array}{c}\text { 95\% Confidence } \\
\text { interval }\end{array}$ \\
\hline$M_{b}[p(\cdot) \cdot c(\cdot)]$ & 155.157 & 0 & 0.37089 & 1 & 3 & $37.18(30.564)$ & $20.87-195.04$ \\
\hline$M_{h}[p(h)=c(h)]^{*}$ & 155.226 & 0.0695 & 0.35823 & 0.9659 & 4 & $29.58(10.44)$ & $21.10-72.30$ \\
\hline$M_{o}[p(\cdot)=c(\cdot)]$ & 155.793 & 0.6369 & 0.26974 & 0.7273 & 2 & $21.86(2.50)$ & $19.65-31.57$ \\
\hline \multicolumn{6}{|c|}{ Model averaged results from top 3 models } & $30.31(20.60)$ & $20.05-140.04$ \\
\hline
\end{tabular}

independently examined the photos for individual identification, both agreed on the $92 \%$ of all the capture events $(n=$ 42 ), and we built the capture histories based on consensus ( $n=39$ ). We excluded the events for which consensus on the individual identity could not be built due to low quality pictures. We identified 19 individuals visually assessed to be 1 year or older ( 5 males, 12 females, 2 of unknown sex).

3.2. Closure Assumption. Program CAPTURE closure test results were consistent with the assumption that the leopard population was closed during the 64-day survey period (Table 2). Additionally, the Stanley and Burnham [57] test was also consistent with the assumption of geographic closure during the sampling period as the model constraining site fidelity (ф) to 1.0 and immigration $(f)$ to 0 , and underlying the $\lambda$ value to be 1 , showed substantially more support than other models (Table 3).

3.3. Abundance Estimates. The discriminant function analysis in program CAPTURE indicated that the $M_{h}$ model, incorporating individual heterogeneity, was the best fit to the data (Table 2). The $M_{h}$ (jackknife estimator) is widely acknowledged as a robust model in estimating abundance of large felids from the photographic capture-recapture analyses $[2,18]$. The average capture probability $(p)$ was 0.08 with an abundance estimate $\widehat{N}(\operatorname{SE}(\widehat{N}))$ of 28 ( \pm SE 6.071) leopards (Table 2). In program MARK, three models (Table 4) accounted for the $100 \%$ of the AIC weights supporting variation in the behavior, heterogeneity, and constant (null model) capture probabilities. Due to imprecise estimates for the $M_{b}$ model and the fact that leopards individuals are unlikely to have constant detectability, we used the model incorporating heterogeneity $\left(M_{h}\right)$ in the abundance estimate $\widehat{N}(\operatorname{SE}(\widehat{N}))$ of $29.58( \pm$ SE 10.44$)$ leopards and capture probability $(p)$ of 0.24 $( \pm$ SE 0.08).

3.4. Density Estimates. Six individual leopards were captured more than once resulting in a MMDM of $5.2 \mathrm{~km}$ and an effective trapping area of $473 \mathrm{~km}^{2}$ using the buffer strip 
TABLE 5: Model selection results from leopard density estimates using photographic capture-recapture data from Parsa Wildlife Reserve in program DENSITY using hazard rate detection function. $g_{0}$ is the capture probability at home range center. $s$ is the spatial scale parameter of capture function. $h 2$ is the 2 -class finite mixture probability for heterogeneity. Akaike's information criterion adjusted for small sample size by $\mathrm{AIC}_{\mathrm{c}} \cdot w_{i}$ represents Akaike weight, while $D^{e}$ is estimated density (per $100 \mathrm{~km}^{2}$ ) and SE represents its standard error. Model averaged density estimates and standard errors are given in bold.

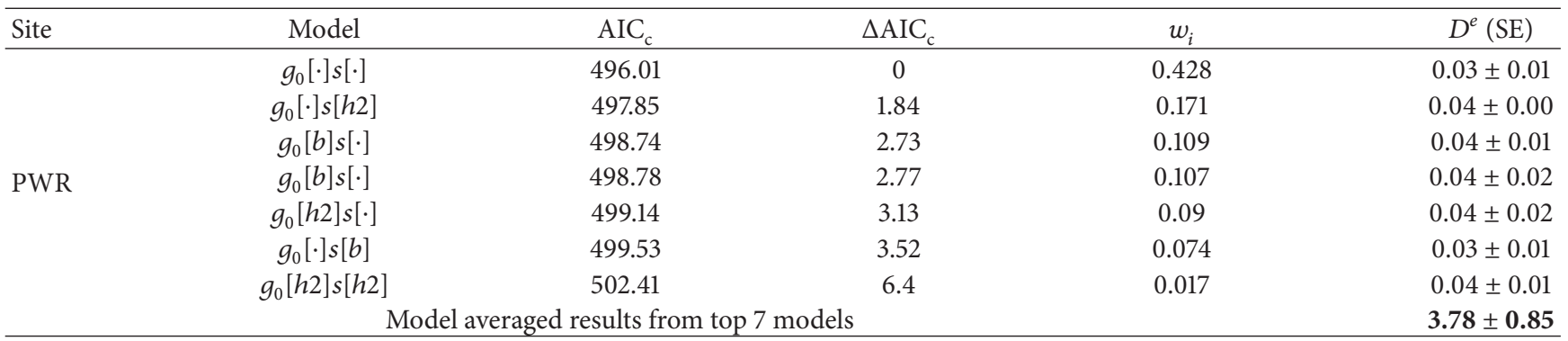

TABLE 6: The posterior summaries from Bayesian spatially explicit capture-recapture (SECR-B) of the model parameters including the leopard density estimates from Parsa Wildlife Reserve implemented in SPACECAP [66] along with Geweke diagnostic parameters. Sigma is the range parameter of the species. lam 0 is the intercept of expected encounter frequency. psi is the ratio of the number of animals present within the state space, $S$, to the maximum allowable number. Nsuper is the number of activity centers in $S$. Density (per $100 \mathrm{~km}^{2}$ ) is Nsuper divided by $S$ and $\mid z$ score| greater than 1.6 implies lack of convergence.

\begin{tabular}{lccccc}
\hline Parameter & $\begin{array}{c}\text { Posterior } \\
\text { mean }\end{array}$ & $\begin{array}{c}\text { Posterior } \\
\text { SD }\end{array}$ & $\begin{array}{c}\text { 95\% Lower } \\
\text { HPD level }\end{array}$ & $\begin{array}{c}\text { 95\% Upper } \\
\text { HPD level }\end{array}$ & $\begin{array}{c}\text { Geweke’s statistics } \\
\mid z \text { score } \mid\end{array}$ \\
\hline Sigma & 2.88 & 0.40 & 2.17 & 3.61 & 1.5975 \\
lam0 & 0.02 & 0.005 & 0.012 & 0.03 & -1.5487 \\
Psi & 0.39 & 0.098 & 0.21 & 0.58 & 0.7407 \\
Nsuper & 77.32 & 18.60 & 44 & 113 & -0.2563 \\
Density & 3.48 & 0.83 & 2.03 & 5.15 & -0.3725 \\
\hline
\end{tabular}

method (using 1/2 MMDM). The density estimates from traditional methods of dividing abundance by the ETA were of $5.61( \pm$ SE 1.30$)$ and $5.93( \pm$ SE 2.15$)$ leopards per $100 \mathrm{~km}^{2}$, from programs CAPTURE and MARK, respectively. We also used the full MMDM, resulting in an effective trapping area of $736.31 \mathrm{~km}^{2}$ and density estimates $3.85( \pm$ SE 0.88$)$ and 4.07 $\left( \pm\right.$ SE 1.46) leopards per $100 \mathrm{~km}^{2}$ with CAPTURE and MARK, respectively.

Spatially explicit models produced much lower estimates than traditional 1/2 MMDM techniques, but they were comparable to the full MMDM methods. The estimated log likelihood and RPSV of 245.04 units and 3,441 m suggested the appropriate buffer size of $15,000 \mathrm{~m}$ for SECR-ML in program DENSITY. Model selection in SECR-ML supported the hazard rate detection function with detectability (at home range center, $g_{0}$ ) and spatial scale (function of movement, s) both constant (null model) (Table 5). There was some support for heterogeneity in the spatial scale as this model was within $2 \triangle \mathrm{AIC}_{\mathrm{c}}$ of the top model. The model averaged density estimate for PWR based on SECR-ML was $3.78( \pm$ SE 0.85) leopards per $100 \mathrm{~km}^{2}$.

Using the SECR-B analysis (SPACECAP program), all model parameters converged based on Geweke diagnostic statistics with $z$ scores not more than 1.6 (Table 6). We obtained the posterior density estimates of the 3.48 ( \pm SE 0.83 ) leopards per $100 \mathrm{~km}^{2}$ and pixelated density map showing the relative animal densities over the animal home range centers (Figure 3).
3.5. Comparison with Leopard Densities in Other Areas. The density point estimates in PWR via traditional methods (5.61 and 6.08) were nearly double the SECR estimates (3.48 and 3.78). However, even the lowest SECR estimate at 3.48 leopards per $\mathrm{km}^{2}$ is highest reported so far in Nepal and is comparable to 3.45 leopards per $100 \mathrm{~km}^{2}$ in the adjacent Chitwan National Park in Nepal. At the regional scale however, our estimates were lower in PWR than the estimates from India (Table 7). Using the traditional 1/2 MMDM approach, which we suspect overestimates density, leopard density in Bhutan was found to be low (1.01 leopards per $100 \mathrm{~km}^{2}$ ) in comparison to 5.41 leopards per $100 \mathrm{~km}^{2}$.

\section{Discussion}

Our approach of conducting a sign survey [2] prior to the camera trap survey aided in fine tuning the survey protocol to maximize detection probability in PWR. In addition to relatively higher probability of capturing leopards present in the sampled area (67\%: $M_{t+1} / \widehat{N}$ ) and capturing $95 \%$ of the leopards in the first 12 days, our approach also demonstrated that operating cameras for short periods (16 days) per block and moving them sequentially to new blocks can provide reliable estimates of leopard abundance and density without violating the closure assumption during the total sampling period of 64 days $[5,18,72]$.

PWR is the only protected area within the forest landscape of the Terai Arc that offers relatively pristine habitats 


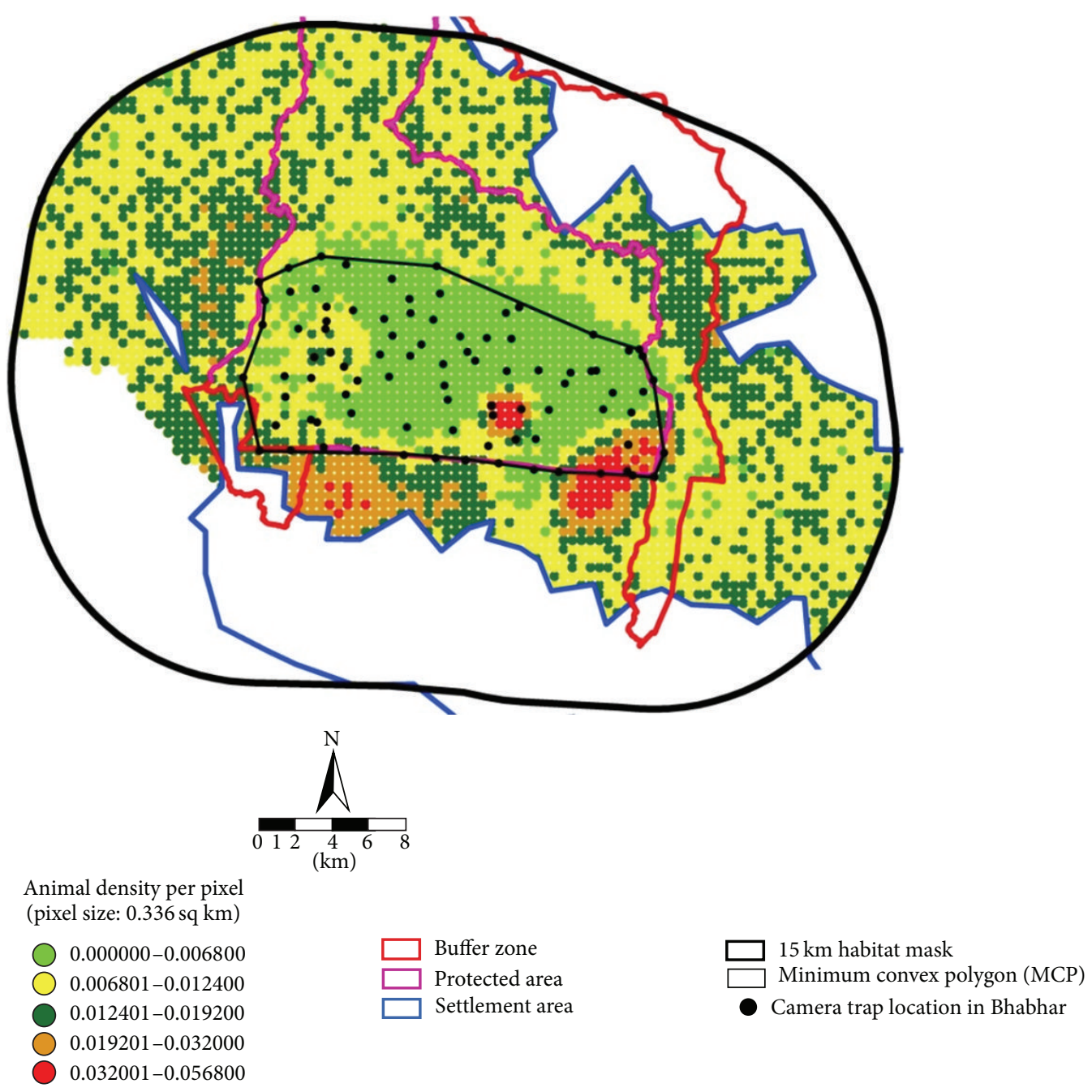

FIGURE 3: A pixelated density map showing relative leopard densities per pixel of size $0.336 \mathrm{~km}^{2}$. The area of MCP (minimum convex polygon) is $289 \mathrm{~km}^{2}$.

for predators in the Bhabhar region. This study constitutes the first attempt to quantify leopard abundance and density from protected areas in the seasonally dry, subtropical deciduous habitat type and Bhabhar physiographic region in the Terai Arc.

Because of the prevailing controversy surrounding estimating animal densities, we used four different approaches to estimate leopard density in the study area. Of the four estimators, leopard densities from SECR-ML and SECR-B models were similar [66] but much lower in comparison to buffer strip method using 1/2 MMDM (Figure 4). Previous studies also indicated that traditional 1/2 MMDM methods overestimate density compared to SECR methods [22, 25, 26, $40,67]$. While we found estimates using the full MMDM to be similar to the SECR models, there is no theoretical basis to justify this inference $[40,73]$ since the $1 / 2 \mathrm{MMDM}$ is meant to represent a home range radius for buffering camera traps. However, it is possible that the extent of the camera trap grid is simply too small to encompass the true leopard home range radius for multiple leopards and hence the
1/2 MMDM underestimates distance moved. For example, a study that used GPS collars and camera traps simultaneously on jaguars showed that actual home range radius was much larger than the $1 / 2 \mathrm{MMDM}$ determined from camera traps [35]. Therefore, the use of the SECR models may be better justified than traditional buffer strip methods in the absence of telemetry/GPS data. Understanding the potential pitfalls of traditional techniques, which may overestimate density, is crucial for managers as they require reliable estimates to make objective assessments of the conservation status of a species at risk.

Program DENSITY allows for selection from multiple possible observation models using an AIC framework and is computationally efficient and relatively quick [41] unlike SPACECAP [74]. We did not evaluate the effect of "sex" as a covariate in density estimates due to inability to determine sex for some of the photographed individual leopards and the inability of program DENSITY to accept missing values. In addition, no feature in the current version of SPACECAP (GUI) allows us to incorporate missing data even though 
TABLE 7: Leopard (Panthera pardus fusca) density estimates (per $100 \mathrm{~km}^{2}$ ) across the array of habitat types from study areas in South Asia based on traditional mean maximum distance moved (MMDM) approaches and spatially explicit capture-recapture (SECR) using maximum likelihood (SECR-ML) and Bayesian (SECR-B) analytical methods. 1/2 MMDM and full MMDM approaches were used in population estimates from program CAPTURE.

\begin{tabular}{|c|c|c|c|c|c|c|}
\hline \multirow{2}{*}{ Site } & \multirow{2}{*}{ Habitat type } & \multicolumn{4}{|c|}{ Density estimates } & \multirow{2}{*}{ Source } \\
\hline & & 1/2 MMDM & Full MMDM & SECR-ML & SECR-B & \\
\hline $\begin{array}{l}\text { Chitwan National Park, } \\
\text { Nepal }\end{array}$ & $\begin{array}{l}\text { Alluvial floodplains } \\
\text { grassland and deciduous } \\
\text { forest }\end{array}$ & $4.06(1.83)$ & $3.48(0.89)$ & & $3.45(0.49)$ & {$[29]$} \\
\hline $\begin{array}{l}\text { Bardia National Park, } \\
\text { Nepal }^{\#}\end{array}$ & $\begin{array}{l}\text { Alluvial floodplains } \\
\text { grassland and deciduous } \\
\text { forest }\end{array}$ & $5(? ?)$ & & & & [89] \\
\hline $\begin{array}{l}\text { Jigme Singye Wangchuck } \\
\text { National Park, Bhutan }\end{array}$ & $\begin{array}{l}\text { Broadleaf to coniferous } \\
\text { forest }\end{array}$ & $1.04(0.01)$ & & & & {$[55]$} \\
\hline $\begin{array}{l}\text { Akole Tahsil, Maharastra } \\
\text { India }\end{array}$ & Irrigated Valley & $6.4(0.78)$ & & & $4.8(1.2)$ & {$[27]$} \\
\hline $\begin{array}{l}\text { Chilla Forest Range-Rajaji } \\
\text { National Park, India }{ }^{\S}\end{array}$ & $\begin{array}{l}\text { Moist and dry deciduous } \\
\text { forest }\end{array}$ & $14.99(6.9)$ & & & & {$[24]$} \\
\hline $\begin{array}{l}\text { Sariska Tiger Reserve, } \\
\text { India }\end{array}$ & Dry deciduous forest & $6.0(0.5)$ & & $7.1(2.0)$ & $5.8(1.1)$ & {$[67]$} \\
\hline $\begin{array}{l}\text { Satpura Tiger Reserve, } \\
\text { India }\end{array}$ & $\begin{array}{l}\text { Dry and moist } \\
\text { deciduous mixed forest }\end{array}$ & $7.3(5.1)-9.3(2.0)$ & $4.2(3.1)-6.2(1.6)$ & $4.04(1.37)-7.21(3.21)$ & & {$[68]$} \\
\hline $\begin{array}{l}\text { Mudumalai Tiger Reserve, } \\
\text { India }\end{array}$ & $\begin{array}{l}\text { Subtropical dry } \\
\text { deciduous forest }\end{array}$ & $28.91(7.22)$ & $13.41(2.67)$ & $13.17(3.15)$ & $13.01(2.31)$ & {$[25]$} \\
\hline $\begin{array}{l}\text { Manas National Park, } \\
\text { India }\end{array}$ & $\begin{array}{l}\text { Alluvial floodplain and } \\
\text { sub-tropical forest }\end{array}$ & $11.30(2.9)$ & & $3.40(0.82)$ & & {$[26]$} \\
\hline $\begin{array}{l}\text { Parsa Wildlife Reserve, } \\
\text { Nepal }\end{array}$ & $\begin{array}{l}\text { Subtropical dry } \\
\text { deciduous forest }\end{array}$ & $5.61(1.30)$ & $3.85(0.88)$ & $3.78(0.85)$ & $3.48(0.83)$ & This study \\
\hline
\end{tabular}

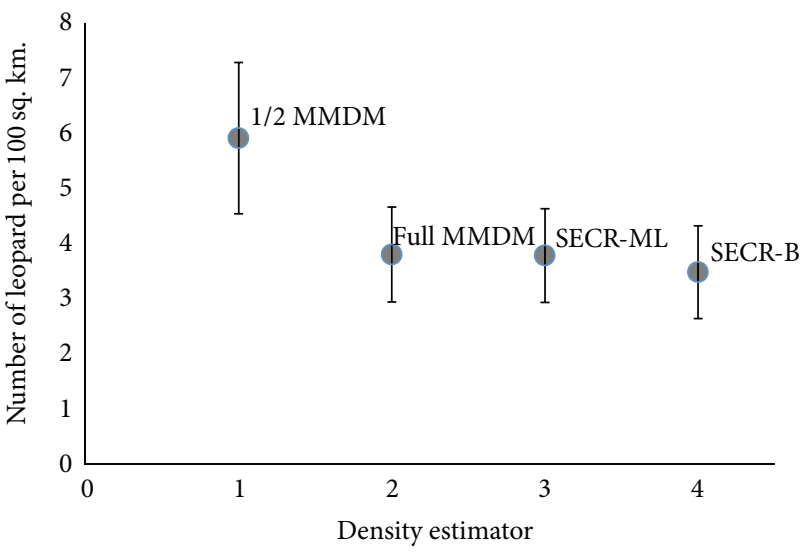

FIGURE 4: Comparative density estimates of leopards in PWR using traditional density estimators that buffer trapping grid by $1 / 2$ or full mean maximum distance moved (MMDM) among camera traps and recently developed spatially explicit capture recapture (SECR) models in a maximum likelihood (SECR-ML) or Bayesian (SECRB) framework.

it is computationally possible with Bayesian analysis [75, 76]. We reported both SECR density estimates in order to compare density estimates across studies that used these techniques [73, 74, 77]. Also, we wanted to evaluate the tradeoff of being able to select among spatial detection models using an information theoretic approach in program DENSITY compared to choosing a spatial detection function in SPACECAP [74]. We expected the posterior estimates from program SPACECAP to be superior as it also reports interval estimates of density as direct probabilities without problematic asymptotic assumptions [27, 45]. The benefits of SPACECAP include that its nonasymptotic assumptions appear to fit the low sample size camera trap data better [45] and it can be extended to open models in future studies. Ultimately we found the estimates from the two SECR methods to be very similar with similar precision.

Our results show that PWR harbors high leopard density similar to other protected areas, namely, Bardia and Chitwan National Park, areas that are considered better habitat. High prey biomass may be the primary reason for unexpectedly high leopard densities in PWR [15], where ungulate prey occurred at $6.6( \pm \mathrm{SE} 1.1)$ individuals per $\mathrm{km}^{2}$ [48]. The current densities of medium- and large-sized prey in PWR are probably not sufficient to support a high density tiger population, assuming an annual kill rate of $3000 \mathrm{~kg}$ per year per tiger and annual biomass cropping rate of $10 \%$ [6]. As a result, tiger density in the reserve is low, at 0.87 tigers per $100 \mathrm{~km}^{2}$ [48], and leopards are, perhaps, able to fully 
exploit their preferred prey, medium- and small-sized prey, perhaps explaining the high density of leopards in PWR. At the regional scale, results of this study demonstrate that SECR leopard densities of 3.48 per $100 \mathrm{~km}^{2}$ in seasonally dry deciduous forest were lower than SECR estimates in similar sites in India. Prey availability and the broad niche width of leopards in forested landscapes could be the reason for their variable densities in the subcontinent.

Baseline population estimates for leopards are essential for monitoring the effectiveness of conservation initiatives [78] and for guiding conservation decisions. In this regard, our findings provide useful insights for leopard conservation both at the local and regional levels. At the local level, our results serve as the benchmark data to assess conservation impacts of the relocation of $c a 100$ households from the core area of PWR. At the regional scale, leopard demographic assessment across this large conservation complex of the Chitwan-Parsa-Valmiki Tiger conservation unit [79, 80], which was established for tigers, can simultaneously provide reliable information on leopard density for the transboundary conservation landscape, following the model provided by the transboundary Manas conservation landscape across India and Bhutan [81]. Hence, long-term monitoring of leopards with camera trap studies, as employed in our study, would be useful to understand conservation status and variation in the population sizes over time and from local to regional scales, thereby informing decision makers in implementing sound conservation management recommendations.

The current Nepalese legislation on wildlife does not recognize the leopard on the protected animal list [82], yet it is one of the most heavily traded species for its skin [83]. The antipoaching strategy designed to protect the tiger and rhinoceros as flagship species in the region [84, 85] should also aid in leopard conservation within protected areas. However, the large swathe of unprotected areas in the human dominated landscape of the Terai Arc [86-88] represents a considerable challenge in terms of the impact of habitat fragmentation [4] and increasing human wildlife conflict in protecting this iconic mesopredator.

\section{Conflict of Interests}

The authors declare that there is no conflict of interests regarding the publication of this paper.

\section{Acknowledgments}

The authors are thankful to the Department of National Parks and Wildlife Conservation for granting permission to carry out this research. They thank the Director General (DNPWC), the Country Representative (WWF Nepal), and the Member Secretary (NTNC) for their support; the core team for their technical support; Parsa Wildlife Reserve staff, BCC/NTNC, and TAL/WWF field staff for their assistance in the survey. Thanks are also due to National Fish and Wildlife Foundation/Save the Tiger Fund, US Fish and Wildlife Service, WWF UK, and WWF International for financial assistance to the project. Kanchan Thapa was supported by WWF US Kathryn Fuller Fellowship and Virginia Tech while preparing the paper. The authors thank Brian Gerber and Dana Morin for their technical advice in the analysis and Brandon Plunkett for helping construct the leopard database. Special thanks are due to Drs: John Seidensticker, Dale Miquelle, and Mark Ryan including two anonymous reviewers for their review and comments in improving the earlier version of this paper.

\section{References}

[1] IUCN, “Red List of Threatened Species Version 2010," International Union for Nature Conservation, http://www.iucnredlist .org/apps/redlist/details/22732/0.

[2] K. U. Karanth and J. D. Nichols, Monitoring Tigers and Their Prey: A Manual for Researchers, Managers and Conservationists in Tropical Asia, Center for Wildlife Studies, New York, NY, USA, 2002

[3] M. E. Sunquist and F. Sunquist, Wild Cats of the World, The University Chicago Press, Chicago, Ill, USA, 2002.

[4] T. Dutta, S. Sharma, J. E. Maldonado, T. C. Wood, H. S. Panwar, and J. Seidensticker, "Fine-scale population genetic structure in a wide-ranging carnivore, the leopard (Panthera pardus fusca) in central India," Diversity and Distributions, vol. 19, no. 7, pp. 760-771, 2013.

[5] K. Thapa, N. M. B. Pradhan, J. Barker et al., "High elevation record of a leopard cat in the Kangchenjunga Conservation Area, Nepal," Cat News, no. 58, pp. 26-27, 2013.

[6] M. E. Sunquist, The Social Organization of Tigers (Panthera tigris) in Royal Chitawan National Park, Nepal, Smithsonian Contributions to Zoology no. 336, Smithsonian Institution Press, Washington, DC, USA, 1982.

[7] K. U. Karanth and M. E. Sunquist, "Prey selection by tiger, leopard and dhole in tropical forests," Journal of Animal Ecology, vol. 64, no. 4, pp. 439-450, 1995.

[8] S. W. Wang and D. W. Macdonald, "Feeding habits and niche partitioning in a predator guild composed of tigers, leopards and dholes in a temperate ecosystem in central Bhutan," Journal of Zoology, vol. 277, no. 4, pp. 275-283, 2009.

[9] D. Veríssimo, T. Pongiluppi, M. C. M. Santos et al., "Using a Systematic Approach to Select Flagship Species for Bird Conservation," Conservation Biology, vol. 28, no. 1, pp. 269-277, 2014.

[10] N. Hairston, F. Smith, and L. Slobodkin, "Community structure, population control and competition," American Naturalist, vol. 94, pp. 421-425, 1960.

[11] E. G. Ritchie and C. N. Johnson, "Predator interactions, mesopredator release and biodiversity conservation," Ecology Letters, vol. 12, no. 9, pp. 982-998, 2009.

[12] K. R. Crooks and M. E. Soulé, "Mesopredator release and avifaunal extinctions in a fragmented system," Nature, vol. 400, no. 6744, pp. 563-566, 1999.

[13] P. Henschel, L. T. B. Hunter, U. Breitenmoser et al., "Panthera pardus," in Proceedings of the IUCN World Conservation Congress, IUCN Red List of Threatened Species, 2013.

[14] G. A. Balme, R. Slotow, and L. T. B. Hunter, "Edge effects and the impact of non-protected areas in carnivore conservation: leopards in the Phinda-Mkhuze Complex, South Africa," Animal Conservation, vol. 13, no. 3, pp. 315-323, 2010. 
[15] K. U. Karanth, J. D. Nichols, N. S. Kumar, W. A. Link, and J. E. Hines, "Tigers and their prey: predicting carnivore densities from prey abundance," Proceedings of the National Academy of Sciences of the United States of America, vol. 101, no. 14, pp. 48544858, 2004.

[16] A. Harihar, D. L. Prasad, C. Ri, B. Pandav, and S. P. Goyal, "Losing ground: tigers panthera tigris in the north-western shivalik landscape of India," Oryx, vol. 43, no. 1, pp. 35-43, 2009.

[17] D. M. Rayan and S. W. Mohamad, “The importance of selectively logged forests for tiger Panthera tigris conservation: a population density estimate in Peninsular Malaysia," ORYX, vol. 43, no. 1, pp. 48-51, 2009.

[18] K. U. Karanth and J. D. Nichols, "Estimation of tiger densities in India using photographic captures and recaptures," Ecology, vol. 79, no. 8, pp. 2852-2862, 1998.

[19] K. U. Karanth, "Estimating tiger Panthera tigris populations from camera-trap data using capture-recapture models," Biological Conservation, vol. 71, no. 3, pp. 333-338, 1995.

[20] K. Kawanishi and M. E. Sunquist, "Conservation status of tigers in a primary rainforest of Peninsular Malaysia," Biological Conservation, vol. 120, no. 3, pp. 329-344, 2004.

[21] P. Wegge, C. P. Pokheral, and S. R. Jnawali, "Effects of trapping effort and trap shyness on estimates of tiger abundance from camera trap studies," Animal Conservation, vol. 7, no. 3, pp. 251256, 2004.

[22] Sunarto,, M. J. Kelly, S. Klenzendorf, M. R. Vaughan, M. B. Hutajulu, and K. Parakkasi, "Threatened predator on the equator: multi-point abundance estimates of the tiger Panthera tigris in central Sumatra," ORYX, vol. 47, no. 2, pp. 211-220, 2013.

[23] J. B. Karki, B. Pandav, S. R. Jnawali et al., "Estimating the abundance of Nepal's largest population of tigers Panthera tigris," Oryx, pp. 1-7, 2013.

[24] A. Harihar, B. Pandav, and S. P. Goyal, "Density of leopards (Panthera pardus) in the Chilla Range of Rajaji National Park, Uttarakhand, India," Mammalia, vol. 73, no. 1, pp. 68-71, 2009.

[25] R. Kalle, T. Ramesh, Q. Qureshi, and K. Sankar, "Density of tiger and leopard in a tropical deciduous forest of Mudumalai Tiger Reserve, southern India, as estimated using photographic capture-recapture sampling," Acta Theriologica, vol. 56, no. 4, pp. 335-342, 2011.

[26] J. Borah, T. Sharma, D. Das et al., "Abundance and density estimates for common leopard Panthera pardus and clouded leopard Neofelis nebulosa in Manas National Park, Assam, India," Oryx, vol. 48, no. 1, pp. 149-155, 2014.

[27] V. Athreya, M. Odden, J. D. C. Linnell, J. Krishnaswamy, and U. Karanth, "Big cats in our backyards: persistence of large carnivores in a human dominated landscape in India," PLoS ONE, vol. 8, no. 3, Article ID e57872, 2013.

[28] J. Seidensticker, M. E. Sunquist, and C. McDougal, "Leopards living at the edge of the Royal Chitwan National Park, Nepal," in Conservation in Developing Countries: Problems and Prospects, J. C. Daniel and J. S. Serrao, Eds., pp. 415-423, Oxford Universitv Press, Bombay, India, 1990.

[29] T. B. Thapa, Habitat suitability evaluation for Leopard (Panthera pardus) using remote sensing and GIS in and around Chitwan National Park, Nepal [Ph.D. thesis], Wildlife Institute of India, Saurashtra University, Rajkot, India, 2012.

[30] M. Odden and P. Wegge, "Kill rates and food consumption of leopards in Bardia National Park, Nepal," Acta Theriologica, vol. 54, no. 1, pp. 23-30, 2009.
[31] M. Israil, M. Al-hadithi, and D. C. Singhal, "Application of a resistivity survey and geographical information system (GIS) analysis for hydrogeological zoning of a piedmont area, Himalayan foothill region, India," Hydrogeology Journal, vol. 14, no. 5, pp. 753-759, 2006.

[32] A. F. O'Connell, J. D. Nichols, and K. U. S. Kaāranta, Camera Traps in Animal Ecology: Methods and Analyses, Springer, New York, NY, USA, 2011.

[33] D. L. Otis, K. P. Burnham, G. C. White, and D. R. Anderson, "Statistical inference from capture data of closed populations," Wildlife Monographs, vol. 2, pp. 1-13, 1978.

[34] B. K. Williams, J. D. Nichols, and M. J. Conroy, Analysis and Management of Animal Populations, Academic Press, California, Calif, USA, 2002.

[35] M. K. Soisalo and S. M. C. Cavalcanti, "Estimating the density of a jaguar population in the Brazilian Pantanal using cameratraps and capture-recapture sampling in combination with GPS radio-telemetry," Biological Conservation, vol. 129, no. 4, pp. 487-496, 2006.

[36] A. Dillon and M. J. Kelly, "Ocelot home range, overlap and density: comparing radio telemetry with camera trapping," Journal of Zoology, vol. 275, no. 4, pp. 391-398, 2008.

[37] K. R. Wilson and D. R. Anderson, "Evaluation of two density estimators of small mammal population size," Journal of Mammalogy, vol. 66, no. 1, pp. 13-21, 1985.

[38] L. R. Dice, "Some census methods for mammals," The Journal of Wildlife Management, vol. 2, no. 3, pp. 119-130, 1938.

[39] A. Dillon and M. J. Kelly, "Ocelot Leopardus pardalis in Belize: the impact of trap spacing and distance moved on density estimates," Oryx, vol. 41, no. 4, pp. 469-477, 2007.

[40] B. D. Gerber, S. M. Karpanty, and M. J. Kelly, "Evaluating the potential biases in carnivore capture-recapture studies associated with the use of lure and varying density estimation techniques using photographic-sampling data of the Malagasy civet," Population Ecology, vol. 54, no. 1, pp. 43-54, 2012.

[41] M. Efford, D. Dawson, and C. Robbins, "DENSITY: software for analysing capture-recapture data from passive detector arrays," Animal Biodiversity and Conservation, vol. 27, no. 1, pp. 217-228, 2004.

[42] J. S. Ivan, Density, Demography and Seasonal Movements of Snowshoe Hares in Central Colorado, Colorado State University, Fort Collins, Colo, USA, 2011.

[43] D. L. Borchers and M. G. Efford, "Spatially explicit maximum likelihood methods for capture-recapture studies," Biometrics, vol. 64, no. 2, pp. 377-385, 2008.

[44] M. G. Efford, D. K. Dawson, and D. L. Borchers, "Population density estimated from locations of individuals on a passive detector array," Ecology, vol. 90, no. 10, pp. 2676-2682, 2009.

[45] J. A. Royle, J. D. Nichols, K. U. Karanth, and A. M. Gopalaswamy, "A hierarchical model for estimating density in camera-trap studies," Journal of Applied Ecology, vol. 46, no. 1, pp. 118-127, 2009.

[46] S. Jha and A. Karn, "Climatic analogues for the administrative districts of Nepal," Tribhuvan University Journal, vol. 23, no. 1, pp. 55-64, 2001.

[47] M. Chetri, Food habits, habitat utilization, and conservation of gaur (Bos gaurus gaurus) in Parsa Wildlife Reserve, Nepal [M.S. thesis], Tribhuvan University, Kathmandu, Nepal, 1999.

[48] J. B. Karki, Occupancy and abundance of tigers and their prey in the Terai Arc Landscape, Nepal [Ph.D. thesis], Wildlife Institute of India, Dehradun, India, 2011. 
[49] DNPWC, Annual Report 2009-2010, Department of National Park and Wildlife Conservation, Babarmahal, Kathmandu, Nepal, 2010.

[50] K. Thapa and S. Lohani, Tiger Went Up the Hill: A Case Study from Parsa Wildlife Reserve, WWF Nepal and University of Missouri, 2007.

[51] S. C. Silver, L. E. T. Ostro, L. K. Marsh et al., "The use of camera traps for estimating jaguar Panthera onca abundance and density using capture/recapture analysis," Oryx, vol. 38, no. 2, pp. 148-154, 2004.

[52] Y. V. Jhala, Q. Qureshi, and R. Gopal, Status of Tigers, CoPredators and Prey in India, National Tiger Conservation Authority, Government of India, Wildlife Institute of India, Dehradun, India, 2008.

[53] A. Harihar, B. Pandav, and S. P. Goyal, "Responses of leopard Panthera pardus to the recovery of a tiger Panthera tigris population," Journal of Applied Ecology, vol. 48, no. 3, pp. 806814, 2011.

[54] S. Miththapala, J. Seidensticker, L. Phillips, S. Fernando, J. Smallwood, and S. Miththapala, "Identification of individual leopards (Panthera pardus kotiya) using spot pattern variation," Journal of Zoology, vol. 218, no. 4, pp. 527-536, 1989.

[55] S. W. Wang and D. W. Macdonald, "The use of camera traps for estimating tiger and leopard populations in the high altitude mountains of Bhutan," Biological Conservation, vol. 142, no. 3, pp. 606-613, 2009.

[56] E. A. Rexstad and K. P. Burnham, User's guide for interactive program CAPTURE, Animal Conservation, Colorado Cooperative Wildlife Research Unit, Colorado State University, Fort Collins, Colo, USA, 1991.

[57] T. R. Stanley and K. P. Burnham, "A closure test for time-specific capture-recapture data," Environmental and Ecological Statistics, vol. 6, no. 2, pp. 197-209, 1999.

[58] R. Pradel, "Utilization of capture-mark-recapture for the study of recruitment and population growth rate," Biometrics, vol. 52, no. 2, pp. 703-709, 1996.

[59] G. C. White and K. P. Burnham, "Program MARK: survival estimation from populations of marked animals," Bird Study, vol. 46, supplement 1, pp. S120-S139, 1999.

[60] S. Pledger, "Unified maximum likelihood estimates for closed capture-recapture models using mixtures," Biometrics, vol. 56, no. 2, pp. 434-442, 2000.

[61] H. Akaike, "Information theory and an extension of the maximum likelihood principle," in Proceedings of the 2nd International Symposium on Information Theory, pp. 267-281, Akademinai Kiado, Budapest, Hungary, 1973.

[62] K. P. Burnham and D. R. Anderson, Model Selection and Multimodel Inference: A Practical Information-Theoretic Approach, Springer, New York, NY, USA, 2nd edition, 2002.

[63] R. R. Parmenter, T. L. Yates, D. R. Anderson et al., "Smallmammal density estimation: a field comparison of grid-based vs. web-based density estimators," Ecological Monographs, vol. 73, no. 1, pp. 1-26, 2003.

[64] J. D. Nichols and K. U. Karanth, "Statistical Concepts: estimating absolute densities of tigers using capture-recapture sampling," in Monitoring Tigers and Their Prey: A Manual for Reseachers, Managers and Conservationists in Tropical Asia, $\mathrm{K}$. U. Karanth and J. D. Nichols, Eds., pp. 121-137, Center for Wildlife Studies, Banglore, India, 2002.

[65] J. A. Royle, K. U. Karanth, A. M. Gopalaswamy, and N. S. Kumar, "Bayesian inference in camera trapping studies for a class of spatial capture-recapture models," Ecology, vol. 90, no. 11, pp. 3233-3244, 2009.

[66] A. M. Gopalaswamy, J. A. Royle, J. E. Hines et al., "Program SPACECAP: software for estimating animal density using spatially explicit capture-recapture models," Methods in Ecology and Evolution, vol. 3, no. 6, pp. 1067-1072, 2012.

[67] K. Mondal, K. Shankar, Q. Qureshi, S. Gupta, and P. Chourasia, "Estimation of population and survivorship of leopard Panthera pardus (Carnivora: Felidae) through photographic capturerecapture sampling in Western India," World Journal of Zoology, vol. 7, pp. 30-39, 2012.

[68] A. Edgaonkar, Ecology of the Leopard (Panthera Pardus) in Bori Wildlife Sanctuary and Satpura National Park, India, University of Florida, Gainesville, Fla, USA, 2008.

[69] C. A. Tredick and M. R. Vaughan, "DNA-based population demographics of black bears in coastal north Carolina and Virginia," Journal of Wildlife Management, vol. 73, no. 7, pp. 1031-1039, 2009.

[70] R. D. C. Team, “The R foundation for statistical computing. Version 3.0.1. Vienna, Austria," 2013.

[71] J. Geweke, "Evaluating the accuracy of sampling-based approaches to the calculation of posterior moments," in Proceedings of the 4th Valencia International Meeting on Bayesian Statistics, pp. 169-194, Oxford University Press, Oxford, UK, 1992.

[72] M. W. Tobler and G. V. N. Powell, "Estimating jaguar densities with camera traps: problems with current designs and recommendations for future studies," Biological Conservation, vol. 159, pp. 109-118, 2013.

[73] M. E. Obbard, E. J. Howe, and C. J. Kyle, "Empirical comparison of density estimators for large carnivores," Journal of Applied Ecology, vol. 47, no. 1, pp. 76-84, 2010.

[74] B. Gardner, J. Reppucci, M. Lucherini, and J. A. Royle, "Spatially explicit inference for open populations: estimating demographic parameters from camera-trap studies," Ecology, vol. 91, no. 11, pp. 3376-3383, 2010.

[75] B. Gardner, J. A. Royle, M. T. Wegan, R. E. Rainbolt, and P. D. Curtis, "Estimating black bear density using DNA data from hair snares," Journal of Wildlife Management, vol. 74, no. 2, pp. 318-325, 2010.

[76] R. E. Russell, J. A. Royle, R. Desimone et al., "Estimating abundance of mountain lions from unstructured spatial sampling," Journal of Wildlife Management, vol. 76, no. 8, pp. 1551-1561, 2012.

[77] A. J. Noss, B. Gardner, L. Maffei et al., “Comparison of density estimation methods for mammal populations with camera traps in the Kaa-Iya del Gran Chaco landscape," Animal Conservation, vol. 15, no. 5, pp. 527-535, 2012.

[78] T. N. E. Gray and S. Prum, "Leopard density in post-conflict landscape, Cambodia: evidence from spatially explicit capturerecapture," The Journal of Wildlife Management, vol. 76, no. 1, pp. 163-169, 2012.

[79] E. Dinerstein, C. Loucks, A. Heydlauff et al., Setting Priorities for the Conservation and Recovery of Wild Tigers: 2005-2015, 2006.

[80] E. Dinerstein, The Return of the Unicornis: The Natural History and Conservation of the Greater One-Horned Rhinoceros, Columbia University Press, New York, NY, USA, 2003.

[81] J. Borah, D. Wangchuk, A. Swargowari et al., "Tigers in the transboundary manas conservation complex: conservation implications across borders," PARKS, vol. 19, p. 51, 2013. 
[82] J. T. Heinen and P. B. Yonzon, "A review of conservation issues and programs in Nepal: from a single species focus toward biodiversity protection," Mountain Research and Development, vol. 14, no. 1, pp. 61-76, 1994.

[83] U. R. Bhuju, R. S. Aryal, and P. Aryal, Report on the Facts and Issues on Poaching of Mega Species and Illegal Trade in Their Parts in Nepal, Transparency International Nepal, Kathmandu, Nepal, 2009.

[84] D. Veríssimo, I. Fraser, J. Groombridge, R. Bristol, and D. C. MacMillan, "Birds as tourism flagship species: a case study of tropical islands," Animal Conservation, vol. 12, no. 6, pp. 549558, 2009.

[85] K. Thapa, S. Nepal, G. Thapa, S. R. Bhatta, and E. Wikramanayake, "Past, present and future conservation of the greater one-horned rhinoceros Rhinoceros unicornis in Nepal," Oryx, vol. 47, no. 3, pp. 345-351, 2013.

[86] E. Wikramanayake, M. McKnight, E. Dinerstein, A. Joshi, B. Gurung, and J. L. D. Smith, "Designing a conservation landscape for tigers in human-dominated environments," Conservation Biology, vol. 18, no. 3, pp. 839-844, 2004.

[87] E. Wikramanayake, E. Dinerstein, J. Seidensticker et al., "A landscape-based conservation strategy to double the wild tiger population," Conservation Letters, vol. 4, no. 3, pp. 219-227, 2011.

[88] S. M. Barber-Meyer, S. R. Jnawali, J. B. Karki et al., "Influence of prey depletion and human disturbance on tiger occupancy in Nepal," Journal of Zoology, vol. 289, no. 1, pp. 10-18, 2013.

[89] M. Odden and P. Wegge, "Spacing and activity patterns of leopards Panthera pardus in the Royal Bardia National Park, Nepal," Wildlife Biology, vol. 11, no. 2, pp. 145-152, 2005. 

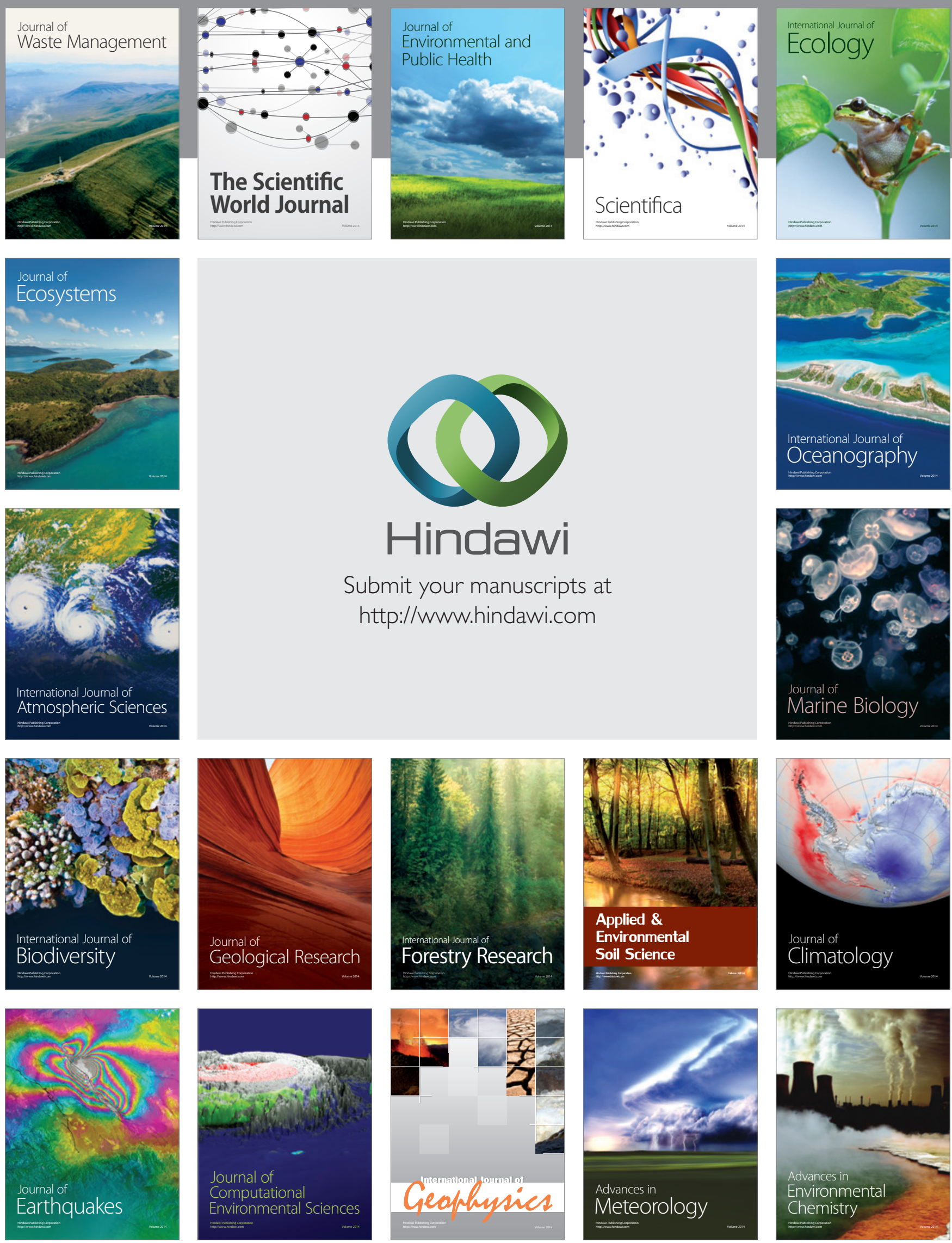